\title{
A Genomic Approach to Develop a New qPCR Test Enabling Detection of the Pyricularia oryzae Lineage Causing Wheat Blast
}

\author{
Maud Thierry, ${ }^{1,2,3}$ Pierre Gladieux, ${ }^{1}$ Elisabeth Fournier, ${ }^{1}$ Didier Tharreau, ${ }^{1,2}$ and Renaud $\operatorname{Ioos}^{3, \dagger}$ \\ ${ }^{1}$ UMR BGPI, Montpellier University, INRA, CIRAD, Montpellier SupAgro, Montpellier, France \\ ${ }^{2}$ CIRAD, UMR BGPI, F-34398 Montpellier, France \\ ${ }^{3}$ ANSES Plant Health Laboratory, Mycology Unit, Domaine de Pixérécourt, Bâtiment E, F-54220 Malzéville, France
}

Abstract

\begin{abstract}
Rapid detection is key to managing emerging diseases because it allows their spread around the world to be monitored and limited. The first major wheat blast epidemics were reported in 1985 in the Brazilian state of Paraná. Following this outbreak, the disease quickly spread to neighboring regions and countries and, in 2016, the first report of wheat blast disease outside South America was released. This Asian outbreak was due to the trade of infected South American seed, demonstrating the importance of detection tests in order to avoid importing contaminated biological material into regions free from the pathogen. Genomic analysis has revealed that one particular lineage within the fungal species Pyricularia oryzae is associated with this disease: the Triticum lineage. A comparison of $81 P y r-$ icularia genomes highlighted polymorphisms specific to the Triticum
\end{abstract}

lineage, and this study developed a real-time PCR test targeting one of these polymorphisms. The test's performance was then evaluated in order to measure its analytical specificity, analytical sensitivity, and robustness. The $\mathrm{C} 17$ quantitative PCR test detected isolates belonging to the Triticum lineage with high sensitivity, down to 13 plasmid copies or 1 pg of genomic DNA per reaction tube. The blast-based approach developed here to study $P$. oryzae can be transposed to other emerging diseases.

Keywords: cereals and grains, emerging disease, field crops, fungi, genome comparison, infraspecific detection, pathogen detection, Pyricularia oryzae, wheat blast
Emerging infectious diseases (EIDs) are defined as diseases that have recently appeared on a new host or in a new area, or whose incidence has rapidly increased (Morse 2001). Various infectious disease agents and hosts may be involved in EIDs. For example, among the EIDs that have recently made the headlines, the Zika virus can cause fetal microcephaly in human populations (Garcez et al. 2016), the bacterium Xylella fastidiosa is responsible for Olive Quick Decline Syndrome (OQDS) in olive trees (Loconsole et al. 2014), and the fungus Geomyces destructans fulfills Koch's postulates for White-Nose Syndrome (WNS), which leads to mass bat mortalities (Fisher et al. 2012). Although these examples belong to different kingdoms and have highly contrasting biological characteristics, they have in common a sudden outbreak in a limited geographical area: the Zika outbreak occurred in 2007 in Micronesia (Ioos et al. 2014), OQDS appeared suddenly in 2010 in Italy (Loconsole et al. 2014), and WNS was described for the first time in March 2007 in New York State (Fisher et al. 2012). Therefore, avoiding the spread of EIDs as soon as possible after their outbreak is essential. To reach this goal, accurate and early diagnosis of the causal agent is a key element in EID management. It allows close monitoring of the pathogen's spread through epidemiological surveillance, thereby enabling a rapid reaction if the pathogen is introduced into novel geographical areas or preventing the trade and exchange of contaminated biological materials whenever possible (detection at points of entry and quarantine measures, for example).

Pyricularia oryzae Cavara (synonym: Magnaporthe oryzae) is a phytopathogenic, hemibiotrophic ascomycete fungus responsible for

${ }^{\dagger}$ Corresponding author: R. Ioos; Renaud.ioos@anses.fr

*The $\boldsymbol{e}$-Xtra logo stands for "electronic extra" and indicates that two supplementary figures and four supplementary tables are published online.

The author(s) declare no conflict of interest.

Accepted for publication 2 August 2019.

(C) 2020 The American Phytopathological Society blast disease in several species of the family Poaceae. Blast symptoms include necrotic lesions on an infected plant's leaves, panicle necks, stems, and grains (Asuyama 1963; Te Beest et al. 2007). P. oryzae encompasses multiple genetic lineages that, together, affect a broad range of Poaceae hosts. Blast has been recorded on more than 25 hosts (crops or wild species) such as rice (Oryza sativa), wheat (Triticum aestivum and Triticum durum), foxtail millet (Setaria italica), or perennial ryegrass (Lolium perenne) (Asuyama 1963; Klaubauf et al. 2014; Maciel 2011; Milazzo et al. 2019). However, spore inoculation experiments have shown that, individually, $P$. oryzae isolates are only pathogenic on a limited range of hosts and the species contains multiple host specificity groups (Couch et al. 2005; Kato et al. 2000; Tosa et al. 2004). Population genetics and phylogenomic analyses of $P$. oryzae isolates collected from different species of Poaceae have revealed that host specificity groups defined from pathogenicity data actually represent multiple divergent lineages within the species. Each lineage is associated with a limited range of specific hosts (Gladieux et al. 2018). For instance, almost all isolates sampled on wheat belong to the same host-specific lineage: the Triticum lineage. Genetic divergence between host-specific lineages is very low (less than $1 \%$ genome-wide pairwise distance, measured as the number of nucleotide differences per kilobase) and genetic exchanges have recently occurred between lineages (Gladieux et al. 2018). However, host specificity is not strict, with some isolates capable of infecting host genera that are different from their host of origin, although generally with less severe symptoms than on the original host (Asuyama 1963; Farman et al. 2017). Some of these opportunistic infections have been well documented, such as that of isolate WBKY11, which was sampled on a single infected wheat head in Kentucky, the United States, despite a previous total absence of wheat blast epidemics in the state. WBKY11 has been described as genetically similar to local isolates infecting ryegrass (Lolium spp.) and belonging to the Lolium lineage, which is the closest hostspecific lineage to that of Triticum (Farman et al. 2017; Gladieux et al. 2018). At the genetic level, host specificity has been linked in some cases to effector-triggered immunity. For example, almost all isolates infecting rice had lost the effector AVR1-CO39 that encodes a protein recognized by rice resistance proteins (Cesari et al. 2013; Couch et al. 2005; Kang et al. 1995), and expression of the 
PWL2 gene inhibits the infection of weeping lovegrass. Effector genes PWT3 and PWT4 have also been shown to prevent infection of wheat varieties carrying the corresponding resistance genes $R w t 3$ and $R w t 4$, respectively (Inoue et al. 2017). Thus, a hypothesis for the appearance of wheat blast is the substantial use of $r w t 3$ wheat varieties (lacking the $R w t 3$ resistance gene and, hence, susceptible to $P$. oryzae isolates carrying $P W T 3$ such as ryegrass isolates), followed by functional losses of the $P W T 3$ gene, allowing a massive outbreak among all $R w t 3$-carrying wheat varieties (Inoue et al. 2017).

Blast is an ancient fungal disease, first recorded on rice in 1637 in China and in 1704 in Japan (Ou 1985). The causal agent was isolated and named in 1891 but had certainly existed long before these dates, and the fungus is now found worldwide. However, before 1985, there were only sporadic reports of this disease among wheat crops (India in 1922, Pakistan in 1943, and Louisiana, the United States in 1973) (Cruz and Valent 2017; Malik and Khan 1944; Mcrae 1922; Rush and Carver 1973). The first wheat blast outbreak was reported in 1985 in the Brazilian state of Paraná, in which major symptoms were observed in wheat fields across six different municipalities. This first epidemic represented a major transition in wheat blast, evolving from causing episodic symptoms to major epidemics. Indeed, this outbreak was followed by a rapid spread to other regions in Brazil (northwestern São Paulo State and southern Mato Grosso do Sul) within a year (Anjos et al. 1996; Goulart 1992; Goulart et al. 2007; Igarashi et al. 1986; Picinini and Fernandes 1990). Soon afterward, the disease spread to three neighboring countries (1996 in Bolivia, 2002 in Paraguay, and 2007 in Argentina) (Cruz and Valent 2017). The first outbreak outside the center of origin was reported in Bangladesh in 2016 and attributed to the introduction of infected seed from South America (Islam et al. 2016; Malaker et al. 2016). Approximately 15,500 ha of wheat were infected by the wheat blast pathogen in Bangladesh in 2016 (Aman 2016; Islam et al. 2016). The P. oryzae isolates causing this recent EID are very aggressive. They greatly harm yield and grain quality, and up to $100 \%$ yield loss has been reported on susceptible wheat varieties under field conditions (Aman 2016; Cruz and Valent 2017; Islam et al. 2019, 2016).

It is of paramount importance to ensure early diagnosis of the $P$. oryzae isolates responsible for wheat blast epidemics (hereafter called "epidemic wheat blast isolates") in order to protect wheat crops (Ceresini et al. 2018). The economic impact of misidentifying wheat blast disease may be substantial. Inaccurate identification of the causal agent can lead to drastic measures such as bans on exportation or the destruction of vast numbers of uncontaminated seed. Conversely, false-negative results (i.e., failure to detect epidemic wheat blast isolates in contaminated material) can start an epidemic in a new area. Given these considerable economic risks, the diagnostic tests used for control and surveillance must fulfill strict conditions: they must discriminate between $P$. oryzae isolates at an infraspecific level in order to distinguish isolates causing epidemic wheat blast from isolates capable of causing only opportunistic wheat infections, despite the isolates sharing identical morphological features in pure culture.

The Triticum lineage identified through phylogenomic analyses includes almost all of the isolates sampled on wheat (Gladieux et al. 2018). In this study, a single isolate had not been sampled on wheat and yet belonged to the Triticum lineage (isolate P29). P29 was collected from a Bromus plant in a wheat field severely affected by blast and was strongly pathogenic on wheat during pathotyping experiments (Pieck et al. 2017). On the other hand, only three isolates sampled from wheat were assigned to the Lolium lineage. Among these three are the previously mentioned U.S. isolate WBKY11 and isolate PY5010, described by Pieck et al. (2017) as mildly pathogenic on wheat under laboratory conditions while being highly pathogenic on Lolium spp. The third isolate is PY86.1, for which no data about its pathogenicity on wheat are available. These elements strongly suggest that the isolates belonging to the Triticum lineage are responsible for wheat blast epidemics and their regrouping within the same lineage implies the existence of genomic regions specific to these isolates. Hereafter, the term "Triticum lineage isolates" is used to denote isolates that were genetically assigned to the Triticum lineage and capable of causing wheat blast epidemics (thus, synonymous with epidemic wheat blast isolates), and "wheatborne isolates" is the term used to refer to those isolated from wheat regardless of their genetic assignment.

DNA-based detection methods such as PCR or real-time PCR are widely used to discriminate pathogens indistinguishable by morphology and have proved their effectiveness in detecting and identifying major plant pathogens, including fungi (Schena et al. 2004). At the species level, classical phylogenetic markers used in fungal taxonomy such as internal transcribed spacers (ITS), translation elongation factors, or $\beta$-tubulins are generally relevant targets for these speciesspecific PCR assays. However, in cases of taxa that have recently diverged such as $P$. oryzae lineages, it is necessary to identify genomic regions with higher variability than those used at the species level (Feau et al. 2018). Furthermore, given the very low level of divergence between $P$. oryzae lineages and the existence of recent genetic exchanges between them (Gladieux et al. 2018), it is unlikely that a single test targeting one genomic region would perfectly meet all of the requirements; for instance, in terms of specificity. A recent study showed that the presence of the MoT3 locus was a discriminant feature of most isolates belonging to the Triticum lineage (Pieck et al. 2017). Therefore, conventional PCR, quantitative PCR (qPCR), and loop-mediated isothermal amplification oligonucleotides have been designed to specifically amplify this genomic region (Pieck et al. 2017; Yasuhara-Bell et al. 2018). However, certain isolates assigned to the Triticum lineage do not carry the MoT3 sequence (for example, isolate BR0032) (Gladieux et al. 2018), suggesting that some Triticum lineage isolates would remain undetectable despite using some of these oligonucleotides (Gupta et al. 2019; Yasuhara-Bell et al. 2019). This pitfall indicates the need to develop a complementary test targeting a different genomic region.

In this study, we (i) searched for new genomic regions carrying DNA polymorphisms that are specific to the Triticum lineage isolates, focusing on alleles of genes known to be involved in pathogenicity to wheat or using a global genomic comparison of $P$. oryzae genomes; (ii) developed a real-time PCR diagnostic test that complements currently existing tools; and (iii) evaluated the specificity of this new test with $P$. oryzae isolates from a broad host range such as $P$. oryzae isolates from previously untested wild hosts such as Eriochloa or Cenchrus spp.

\section{Materials and Methods}

Fungal genome assembly. In all, 81 published Pyricularia genome assemblies (Gladieux et al. 2018) were compared: 4 P. grisea genomes, $1 P$. pennisetigena genome, and $76 P$. oryzae genomes. Of the latter, 20 belonged to the Triticum lineage, 19 had been collected from Triticum spp., and 1 was from Bromus tectorum (isolate P29) (Supplementary Table S1).

Fungal DNA extraction. DNA was extracted from a collection of 114 fungal isolates, including $110 P$. oryzae. Of the latter, 30 had been isolated from wheat and 80 had been sampled from 21 different Poaceae genera. Some of these isolates were sequenced and genetically assigned to a host-specific lineage by Gladieux et al. (2018) (Supplementary Table S2). Upstream of this study, a population genetic analysis was conducted on 90 wheat-borne isolates collected in Brazil and Bolivia between 1989 and 2013. This analysis allowed us to maximize the genetic diversity of the wheat-borne isolates tested in this study, retaining one isolate for each multilocus genotype detected. The integrity of all 114 DNA extracts was verified by their successful amplification by PCR using ITS5-4, ITS1-4, or RPB2 (5cR/7cR) primers (O'Donnell et al. 2007; White et al. 1990) prior to further testing.

Construction of plasmids for use as positive control. The genomic region targeted by the $\mathrm{C} 17$ primer set was amplified with forward and reverse primers located upstream and downstream: seqF_C17 (5'-TGC GTC CCA AGA TTT TCG TGA-3') and seqR_C17 (5'CTA CGC ATG GTG GGG AGA GA-3'). The amplicon was inserted in a pCR4-TOPO plasmid (Invitrogen, Carlsbad, CA, U.S.A.), which was used to transform chemically competent TOP10 cells (Invitrogen), according to the manufacturer's instructions. The 
bacterial cells were then subcultured overnight at $37^{\circ} \mathrm{C}$, and the plasmids were purified using a NucleoSpin Plasmid kit (MachereyNagel, Düren, Germany). The plasmid solution was used as a positive control for $\mathrm{C} 17$ real-time PCR.

Seed samples. $P$. oryzae-free wheat seed (variety Filon) from a field in Montpellier, France were used for the negative control and artificial inoculation with the pathogen. The seed were provided by C. Rudelle (GEVES, Montpellier, France). A culture of Triticum lineage isolate BL0044 was grown on potato dextrose agar (PDA) medium at $26^{\circ} \mathrm{C}$, in a level 3 biosafety room at ANSES, Malzéville, France. A plug of mycelium was taken from the edge of the actively growing culture and used to inoculate a sample of 400 wheat grains laid over $15 \mathrm{ml}$ of potato dextrose broth (PDB) in a sterile Petri dish. After $48 \mathrm{~h}$ of incubation, an additional $15 \mathrm{ml}$ of PDB was added and the mixture was ground in a $125-\mathrm{ml}$ sterilized glass bowl using a Microtron MB 550 laboratory mixer (Kinematica, Lucerne, Switzerland). A negative control seed sample was also prepared, using a sterile PDA plug for inoculation. For each seed sample, one 500- $\mu 1$ sample was taken from the homogenate using a truncated 1-ml pipet tip and used for total DNA extraction with NucleoSpin Plant II DNA extraction kit (Macherey-Nagel), following the manufacturer's recommendations. Triticum lineage was detected by real-time PCR under optimized conditions, using these raw DNA extracts as templates.

Plant varieties for pathogenicity tests. $P$. oryzae isolates were tested for pathogenicity on wheat variety Thésée, which is susceptible to wheat blast, and on a commercial mixture of three ryegrass varieties (Pronto, Fandango, and Funk) used as susceptibility checks. Compatibility between $P$. oryzae isolates and wheat or ryegrass was evaluated under controlled conditions, by inoculating wheat leaves (5 plants/isolate) or ryegrass leaves (more than 10 plants/ isolate) with a conidial suspension using two protocols. First, as described for rice by Gallet et al. (2016), $10 \mathrm{ml}$ of conidial suspension (20,000 conidia/ml) with $1 \%$ gelatin was sprayed on 2-week-old seedlings for each isolate. This method of inoculation is softer and is closer to natural inoculation but was not adapted to inoculate epidemic wheat blast isolates as positive controls in our biosafety facilities. Second, a suspension of 50,000 conidia/ml was applied using a brush in a delimited wheat leaf region. This method may be deemed as more invasive because brush movements can injure leaf tissues but it enabled the introduction of positive controls (isolates BR0032 and BL0028) in the compatibility experiment. In both cases, the inoculated plants were kept overnight at $27^{\circ} \mathrm{C}$ and $100 \%$ humidity and then for a further 7 days with alternation of day and night $(13 \mathrm{~h}$ at $27^{\circ} \mathrm{C}$ and $11 \mathrm{~h}$ at $21^{\circ} \mathrm{C}$, respectively) before noting symptoms.

Search for PWT3 and PWT4 alleles in P. oryzae genomes. To determine whether the sequences of the avirulence genes PWT3 and PWT4 could be used as genomic hallmarks of the Triticum lineage, BLASTN (version 2.6.0) was used to search for alleles of these genes in the $81 P$. oryzae genomes (options -task blastn and e-value $0.0001)$. The query sequences used were the nucleotide sequences of the avirulent alleles; that is, A0 for PWT3 (accession number LC202650.1) and Br58 for PWT4 (accession number LC202655.1). Some of the DNA sequences located upstream or downstream of these genes were repeated multiple times in the assembled genomes, such as positions 1 to 159 and 531 to 603 for the PWT3 A0 allele, and positions 1 to 211 and 853 to 927 for the PWT4 Br58 allele. Therefore, every hit that only mapped these repeated regions was removed. In addition, when two parts of the gene were identified on the same scaffold (indicating a large insertion in the gene sequence) or in different scaffolds on the assembly (due to either a genomic rearrangement or an assembly issue), the sequences were merged. All sequences were aligned with Muscle (version 3.8.31) and compared (data not shown).

Comparison of $\boldsymbol{P}$. oryzae genomes to identify DNA regions unique to the Triticum lineage. To detect DNA regions that were specific to the Triticum lineage, we designed a bioinformatics approach using PYTHON scripts and based on comparing 81 previously published assembled genomes. We focused on polymorphisms that were fixed in the Triticum lineage. The genome of isolate BR0032 sampled from wheat and belonging to the Triticum lineage was chosen as a reference. This genome was fragmented into sequences of 500 nucleotides with $250 \mathrm{bp}$ overlap. To select fragments of interest, we conducted a homology analysis with other genomes using BLASTN (version 2.6.0), specifying -task blastn. Fragments were then selected if two criteria were fulfilled: (i) a sequence strictly identical to the candidate fragment was found in each of the genomes belonging to the Triticum lineage and (ii) no sequence $100 \%$ identical to the candidate fragment was found in any of the genomes belonging to other hostspecific lineages. A first screening of the fragments was performed using only three genomes (from Triticum, Lolium, and Oryza lineages), and every fragment retained was then screened using the other 78 genomes. Finally, for each selected fragment, the homologous sequence in each assembled genome was extracted and all the sequences were aligned using Muscle (version 3.8.31). This study's bioinformatics analysis is summarized and sketched in Figure 1.

Development of a qPCR diagnostic test. Primer design. Candidate primers and probes were designed to specifically amplify DNA from the Triticum lineage genotypes, targeting the Triticum lineagespecific positions identified by bioinformatics analyses. Forward and reverse primers were designed so as to amplify a DNA fragment of 90 to $120 \mathrm{bp}$ using PCR. The polymorphisms specific to the Triticum lineage were preferentially positioned at the $3^{\prime}$ end of the forward and reverse primers, in order to enhance PCR specificity. Primers and $5^{\prime} 6-F A M / 3^{\prime} B H Q-1$ hydrolysis probes were custom synthesized by Eurogentec (Seraing, Belgium).

Screening candidate primers for inclusivity and specificity. Inclusivity (i.e., ability to target all epidemic wheat blast isolates) and specificity (i.e., ability to avoid cross-reacting with nontarget DNA) were the main criteria for primer selection. Primers were first screened for specificity and inclusivity using conventional PCR. These two parameters were assessed using DNA from a small panel consisting of seven isolates sampled on different hosts (three on ryegrass: AG0064, PL2-1, and 365; one on finger millet: IN0113; one on rice: BR0019; and two wheat-borne isolates: AG0103 and BL0093). PCRs to enable screening used the qPCR core kit No ROX (Eurogentec) with the following reaction mixture: $2 \mu \mathrm{l}$ of DNA template $(0.5 \mathrm{ng} / \mu \mathrm{l}), 1 \times$ polymerase buffer, $5 \mathrm{mM} \mathrm{MgCl} 2$, $0.3 \mu \mathrm{M}$ forward and reverse primers, $4 \times 0.2 \mathrm{mM}$ dNTPs, HotGoldStar DNA polymerase at $0.025 \mathrm{U} / \mu 1$, and molecular-grade water to $20 \mu$ l. The PCR conditions were $10 \mathrm{~min}$ at $95^{\circ} \mathrm{C}$, then 40 cycles of $15 \mathrm{~s}$ at $95^{\circ} \mathrm{C}$ and $55 \mathrm{~s}$ at $60^{\circ} \mathrm{C}$. Amplification products were resolved by ethidium bromide staining after $50 \mathrm{~min}$ of electrophoresis on $2 \%$ agarose gel.

Specificity and inclusivity were then further assessed by combining the best candidate-specific primer pairs with a hydrolysis probe in real-time PCR. The hydrolysis probes were designed to target polymorphisms specific to the Triticum lineage, whenever possible. The specificity of primer and probe combinations was tested using DNA from a larger panel of 114 isolates, including 110 P. oryzae isolates sampled on 21 different host genera. Real-time PCRs were carried out in a $20-\mu l$ reaction volume containing $2 \mu \mathrm{l}$ of DNA template $(0.5 \mathrm{ng} / \mu \mathrm{l}), 1 \times \mathrm{qPCR}$ core kit No ROX (Eurogentec) polymerase buffer, $5 \mathrm{mM} \mathrm{MgCl}, 0.3 \mu \mathrm{M}$ forward and reverse primers, $0.1 \mu \mathrm{M}$ probe, $4 \times 0.2 \mathrm{mM}$ dNTPs, HotGoldStar DNA polymerase at $0.025 \mathrm{U} / \mu \mathrm{l}$, and molecular-grade water to $20 \mu \mathrm{l}$. The following PCR profile was used: $10 \mathrm{~min}$ at $95^{\circ} \mathrm{C}$, then 40 cycles of $15 \mathrm{~s}$ at $95^{\circ} \mathrm{C}$ and $55 \mathrm{~s}$ at $60^{\circ} \mathrm{C}$. The specificity and inclusivity of the MoT3 test were assessed on the same 114-isolate panel, using the PCR conditions described above.

$C 17-F /-R /-P$ specific test performance values. For the $\mathrm{C} 17$ primer/ probe combination, the master mix composition and cycling conditions were adjusted to optimize specificity and sensitivity (mean cycle threshold $[\mathrm{Ct}]$ values). Optimal real-time PCR conditions were as follows: $2 \mu$ l of DNA template, $1 \times$ polymerase buffer (qPCR core kit No ROX; Eurogentec), $5 \mathrm{mM} \mathrm{MgCl} 2,0.3 \mu \mathrm{M}$ forward C17-F (5'CGA TAG AAA CTT GAG GAA GAT CAA GTA AG-3') and reverse C17-R (5'-TCA CCG AGA GAT GTG CCA C-3') primers, $0.05 \mu \mathrm{M}$ C17-P probe (5'-FAM- TCG CTA ACA ATG TCC ACC CCG CC-BHQ1-3'), $4 \times 0.2 \mathrm{mM}$ dNTPs, HotGoldStar DNA polymerase at $0.025 \mathrm{U} / \mu \mathrm{l}$, and molecular-grade water to $20 \mu \mathrm{l}$. PCR cycles were identical to those used for primer screening, except that the 
hybridization or polymerization temperature was increased to $65^{\circ} \mathrm{C}$. The following performance criteria were assessed: analytical specificity, analytical sensitivity, transferability, and robustness. Analytical specificity, analytical sensitivity, and robustness measures were determined with data generated by a Stratagene Mx3005P realtime thermocycler (Agilent Technologies, La Jolla, CA, U.S.A.) and extracted using Mx3005P software (V4.10) with a threshold set at 400. Analytical specificity was assessed using duplicated reactions using genomic DNA (gDNA) from the 114 P. oryzae isolates previously adjusted to $0.5 \mathrm{ng} / \mu \mathrm{l}$. Analytical sensitivity was assessed using a 10-fold dilution series of the plasmid DNA-positive controls containing the $\mathrm{C} 17-\mathrm{F} / \mathrm{R}$ amplicon diluted in ultrapure water and with a dilution of gDNA from isolates BR0032 and BL0028. The dilution series ranged from $13 \times 10^{3}$ to 1.3 plasmid copies/ $\mu 1$ and gDNA at $0.5 \mathrm{ng} / \mu \mathrm{l}$ to $0.05 \mathrm{pg} / \mu \mathrm{l}$. The limit of detection (LOD) was determined as the minimal quantity of target DNA that could be consistently amplified by qPCR (at least 10 replicates). A standard curve was constructed based on these data.

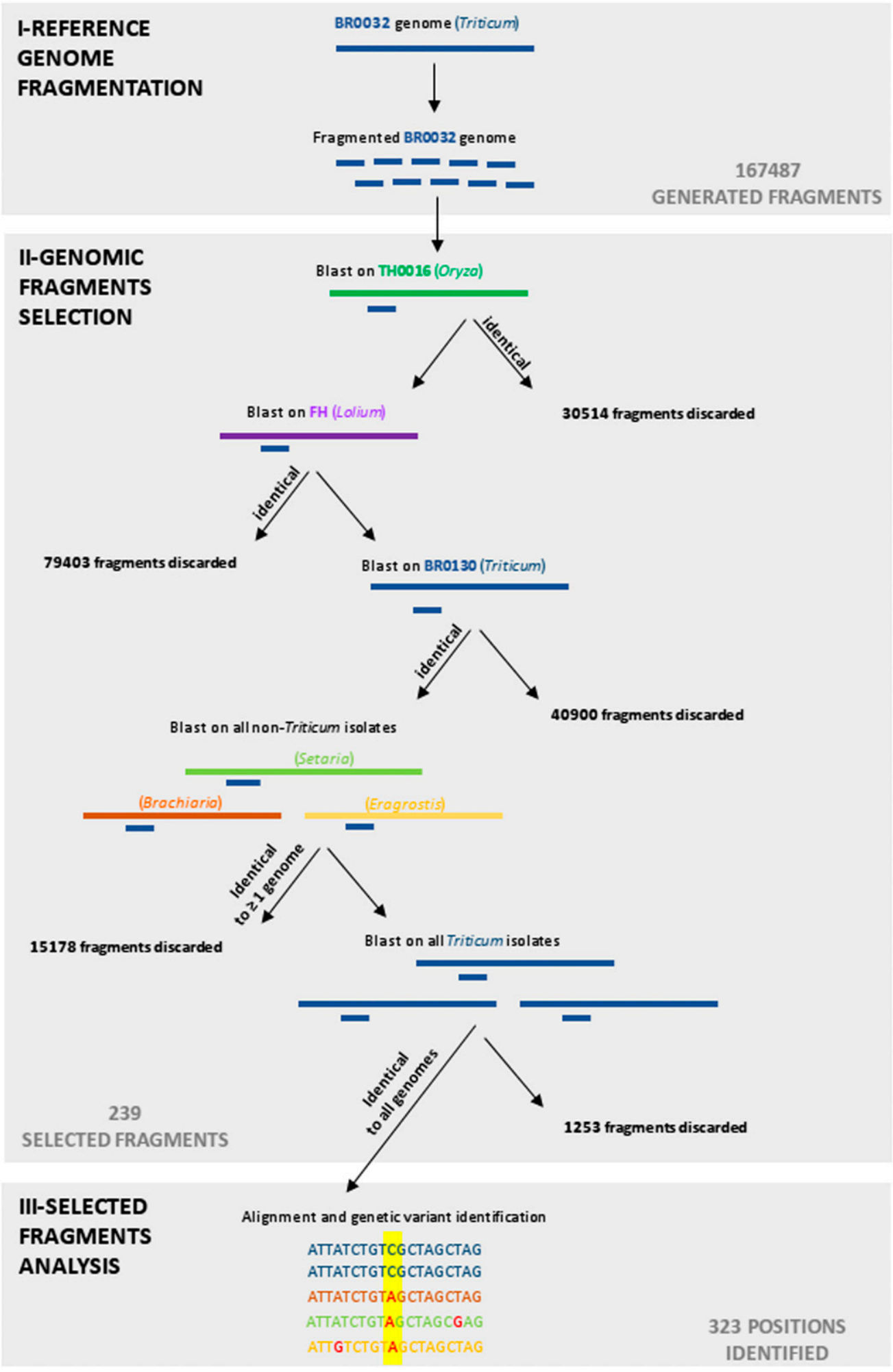

Fig. 1. Bioinformatics approach used to identify polymorphisms specific to the Triticum lineage of Pyricularia oryzae. Colors of the schematic genomes represent isolate lineages. 
The test's transferability was assessed using three replicates with different brands of qPCR reagents: $2 \times$ Takyon for Probe Assay, No ROX blue (Eurogentec), LightCycler 480 Probes Master (Roche, Meylan, France), and Takyon Core Kit for Probe Assay, No ROX blue (Eurogentec), another type of thermocycler (Rotor-Gene 6500; Corbett Research, Mortlake, Australia), and a different laboratory (ANSES Plant Health Laboratory). To assess the robustness of the qPCR assay, several reaction parameters were deliberately modified and the assay was carried out using 10 replicates of different DNA templates. The qPCR assay's robustness was challenged by varying the reaction volume or DNA template volume by $\pm 10 \%$, and slightly varying the hybridization temperature $\left( \pm 2^{\circ} \mathrm{C}\right)$ to verify whether the test could withstand experimental variations without compromising sensitivity and specificity. Transferability and robustness were determined using a panel of different DNA types as templates. The panel consisted of (i) target DNA close to the LOD

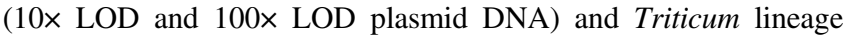
BL0044 gDNA at $0.5 \mathrm{ng} / \mu \mathrm{l}$, (ii) nontarget DNA (AG0064 ryegrass isolate at $0.5 \mathrm{ng} / \mu \mathrm{l}$ and IN0113 finger millet isolate gDNA), and (iii) total DNA extracted from healthy wheat seed and wheat seed artificially inoculated with BL0044.

\section{Results}

$P W T 3$ and $P W T 4$ avirulence genes are not specific markers to the Triticum lineage. The PWT3 and PWT4 alleles (including presence or absence polymorphisms) were examined in 81 published and assembled genomes, including $76 P$. oryzae genomes, in order to determine whether alleles of these effectors can be diagnostic of the Triticum lineage. The PWT4 avirulence gene sequence was absent in 50 of the 81 genomes studied, including 14 isolates from the Triticum lineage and 36 isolates from other lineages. The complete and functional allele (i.e., the complete coding sequence and its upstream region) was only identified in the genome of isolate $\mathrm{Br} 58$, as already described by Inoue et al. (2017). Other genomes carried truncated alleles lacking various genic regions; one of these alleles was shared among isolates of Lolium lineage and certain isolates of the Triticum lineage (T25 and Br48). PWT3 was found in all genomes except $P$. oryzae isolate EI9411 sampled on Eleusine spp. and $P$. pennisetigena isolate Pm1 sampled from Pennisetum spp. Various PWT3 gene alleles were retrieved from these assemblies, including alleles displaying large insertions or gene fragmentation (i.e., fragments of the gene on different assembly scaffolds).

Sequence comparison, based on the regions conserved between different PWT3 alleles, highlighted that Triticum lineage isolates shared alleles with nonTriticum lineage isolates such as Lolium or Stenotaphrum lineage isolates. For both PWT3 and PWT4, some alleles were shared between isolates of the Triticum lineage and other lineages. Therefore, PWT3 and PWT4 avirulence genes were not suitable for designing markers specific to the Triticum lineage and were not further used in developing a diagnostic test.

Comparative genomics identifies candidate genetic markers unique to the Triticum lineage. The genome of isolate BR0032, used as a reference for the Triticum lineage, was fragmented in silico into 167,487 fragments. Our bioinformatics approach retained only fragments for which (i) a strictly identical (100\% identity over $500 \mathrm{bp}$ ) sequence was found in all genomes from the Triticum lineage and (ii) hits in genomes from other lineages had $<100 \%$ identity (Fig. 1). In total, 239 fragments were selected and their corresponding alignments were generated. At the end of this process, 323 polymorphisms specific to the Triticum lineage were identified. These positions were spread over 135 fragments belonging to four distinct scaffolds of the reference genome BR0032 (Supplementary Table S3).

Design of Triticum lineage-specific oligonucleotide candidates. In total, 34 primer pairs (forward and reverse primers) were designed to specifically amplify the DNA of Triticum lineage isolates using PCR. These oligonucleotide combinations target the different regions on the BR0032 genome that carry some of the Triticum lineage-specific positions identified by our bioinformatics scripts. As much as possible, the regions selected (i) were physically distant from each other within the BR0032 genome and (ii) carried several polymorphisms in order to improve the oligonucleotides' specificity. Oligonucleotide sequences are given in Supplementary Table S4.

Prescreening of inclusive and specific primer sets. Among the 34 primer pairs tested, 14 (41\%) yielded a stronger amplification signal with DNA from the two wheat-borne isolates included in the small panel, confirming by PCR the in silico results provided by the bioinformatics approach. However, of these 14 primer pairs, only 5 (C5, C7, C9, C17, and C19) generated no cross-reaction with DNA from the nontarget isolates in our small panel, and 4 of these (C5, C9, $\mathrm{C} 17$, and C19) were selected for further analyses. An associated hydrolysis probe was designed for use in combination with each selected primer pair in real-time PCR.

Final selection and evaluation of Triticum lineage-specific oligonucleotides. The four selected oligonucleotide combinations target sequences located in different regions of genome BR0032. Combinations $\mathrm{C} 5, \mathrm{C} 9$, and $\mathrm{C} 17$ target scaffold 15 of genome BR0032 (with an approximately 29,500-bp distance between C9 and C5 and an approximately 109,000-bp distance between C5 and C17), whereas combination C19 targets scaffold 17 . The previously published primer/probe combination MoT3_1F, MotT3_1R, and MoT3_FAM2, which targets epidemic wheat blast isolates of $P$. oryzae (Pieck et al. 2017), was also included for comparison. The specificity and inclusivity of the combinations were assessed using realtime PCR, with a larger panel of 114 DNA extracts. The results showed that none of them were able to achieve full inclusivity and full specificity. In our PCR conditions, combinations MoT3 and C19 failed to yield positive results with DNA from 2 and 3 different wheat-borne isolates, respectively, out of the 30 in our panel, whereas they yielded cross-reactions with a single but different DNA extract from nontarget isolates (Fig. 2). When PCR used the three oligonucleotide combinations designed on scaffold 15 (C5, C9, and C17), it successfully amplified DNA from $100 \%$ of the 30 wheat-borne isolates tested. However, using these combinations, cross-amplifications were observed with DNA from isolates sampled on other host plants (Fig. 2). Based on these results, combination $\mathrm{C} 17$ was selected because, under our PCR conditions, it successfully amplified DNA from all 30 wheat-borne isolates in our panel yet yielded the lowest rate of cross-reactions (only four nontarget isolates: CR0023, CR0057, JP0033, and IN0113). After adjusting the primer mix composition and increasing the hybridization temperature to $65^{\circ} \mathrm{C}$, all $30 \mathrm{DNA}$ extracts from wheat-borne isolates were amplified (with $\mathrm{Ct}$ values ranging from 25.74 to 30.69 , including isolate $\mathrm{P} 29$, sampled from Bromus spp. but belonging to the Triticum lineage), whereas late amplification was not observed with DNA from isolate IN0113 sampled from Eleusine spp. (Fig. 2).

C17-F/-R/-P test performance. Test sensitivity. The analytical sensitivity of test $\mathrm{C} 17$ was determined by analyzing three replicates of a serial 10-fold dilution in ultrapure water of gDNA of the isolates BR0032 and BL0028 or a dilution of the PCR target inserted into plasmid DNA. The test successfully amplified $100 \%$ of the replicates down to $1 \mathrm{pg}$ of gDNA for both isolates and down to 13 plasmid copies/reaction tube (Fig. 3). This limit of detection was confirmed by a further test using 10 replicates. The regression coefficient $\left(R^{2}\right)$ was 0.981 , showing a good correlation between $\mathrm{Ct}$ values and the initial quantity of target DNA loaded (Fig. 3). As a proof of concept, DNA extracted from noninoculated seed and DNA extracted from seed artificially inoculated with isolate BL0044 were tested by real-time PCR using the C17-F/-R/-P set. The test consistently detected BL0044 DNA in the inoculated seed, whereas no signal was observed with the control seed sample.

C17 test robustness and transferability. When minor changes in volume and temperature were applied to the original PCR conditions, the mean $\mathrm{Ct}$ values obtained with the DNA templates tested were significantly modified $(P$ value $=2.2 \mathrm{e}-16)$. However, $\mathrm{Ct}$ values measured under these different conditions are of the same order of magnitude without altering the qualitative results (+/-) and, thus, corroborate the specificity and sensitivity of the $\mathrm{C} 17$ test. An exception to this was when late amplification of the DNA from isolate IN0113 $(\mathrm{Ct}=38.83)$ was observed for 1 of the 10 replicates when 
the hybridization temperature was decreased to $63^{\circ} \mathrm{C}$. The test's transferability in terms of other lab conditions was evaluated by changing the type of thermocycler, the real-time master mix brand, and the operator. In most cases, specificity and sensitivity of the $\mathrm{C} 17$ test were not qualitatively affected by these modifications. However, it is worth mentioning that changing the real-time PCR master mix type led to late amplifications of DNA from the IN0113 Eleusine isolate. Quantitatively, $\mathrm{Ct}$ values were generally improved (i.e., determined earlier) using the Rotorgene thermocycler. Data are presented in Figure 4.

Characterizing cross-amplified taxa. Because DNA from isolates CR0023, CR0057, and JP0033 were consistently crossamplified by the C17-F/-R/-P test, PCR primers were designed to flank the region amplified by primer set $\mathrm{C} 17$ in order to

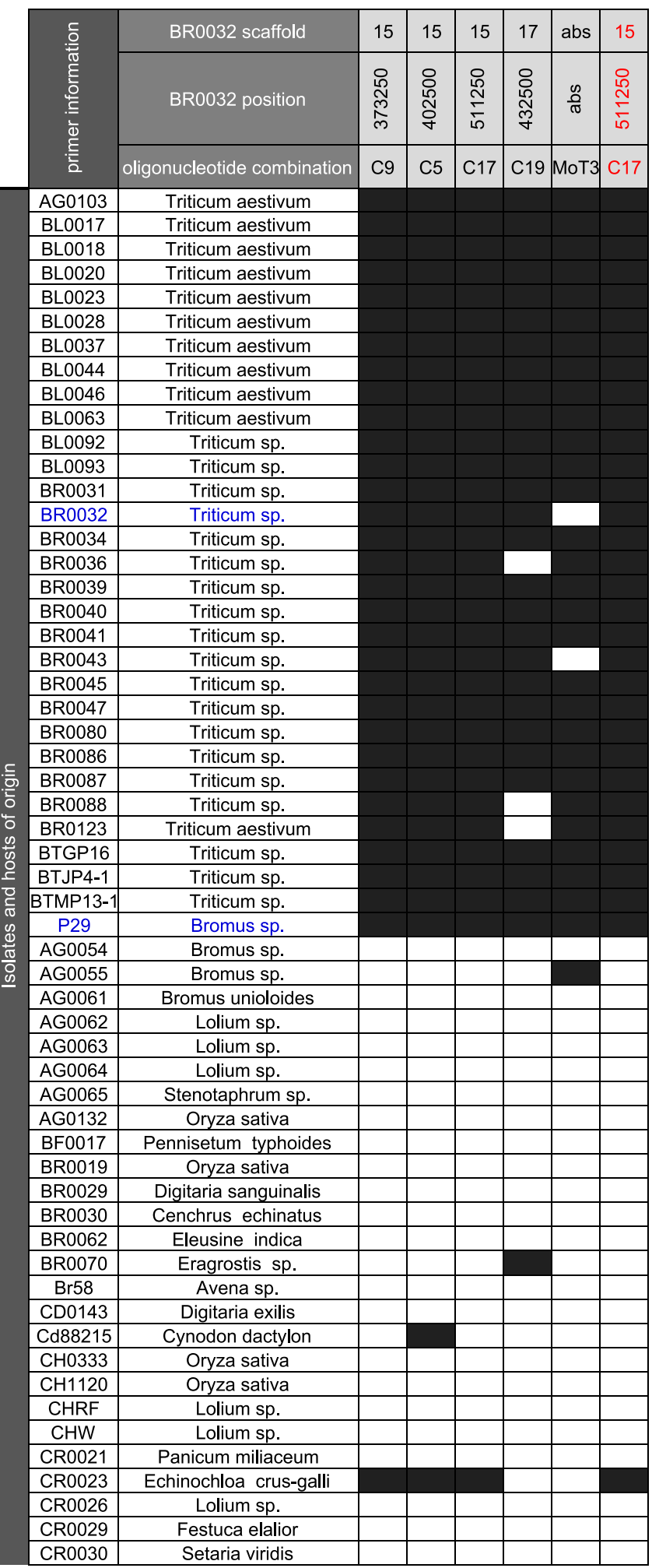

\begin{tabular}{|c|c|c|c|c|c|c|c|}
\hline 등 & BR0032 scaffold & 15 & 15 & 15 & 17 & abs & 15 \\
\hline 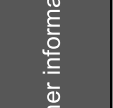 & BR0032 position & 怘 & $\begin{array}{l}\text { O̊ } \\
\stackrel{\leftrightarrow}{N} \\
\text { ô }\end{array}$ & $\stackrel{\stackrel{\circ}{N}}{\stackrel{\text { in }}{亡}}$ & 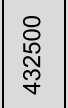 & 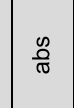 & 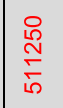 \\
\hline 言 & oligonucleotide combination & $\mathrm{Cg}$ & C5 & C17 & C19 & МоТ3 & C17 \\
\hline CR0031 & Setaria italica & & & & & & \\
\hline CR0057 & Lolium sp. & & & & & & \\
\hline EG0028 & Cyperus rotundus & & & & & & \\
\hline $\mathrm{FH}$ & Lolium sp. & & & & & & \\
\hline FR0013 & Oryza sp. & & & & & & \\
\hline FR1069 & Lolium sp. & & & & & & \\
\hline GG11 & Lolium sp. & & & & & & \\
\hline GN0001 & Zea mays & & & & & & \\
\hline GR0001 & Ctenanthe oppenheimiana & & & & & & \\
\hline GY0011 & Oryza sativa & & & & & & \\
\hline $\mathrm{HO}$ & Lolium sp. & & & & & & \\
\hline IN0003 & Panicum repens & & & & & & \\
\hline IN0005 & Panicum maximun & & & & & & \\
\hline IN0022 & Setaria sp. & & & & & & \\
\hline IN0023 & Setaria sp. & & & & & & \\
\hline IN0082 & Oryza sativa & & & & & & \\
\hline IN0108 & Setaria sp. & & & & & & \\
\hline IN0113 & Eleusine $\mathrm{sp}$. & & & & & & \\
\hline IN0115 & Oryza sativa & & & & & & \\
\hline IR0013 & Zea mays & & & & & & \\
\hline IR0015 & Zea mays & & & & & & \\
\hline IR0095 & Zea mays & & & & & & \\
\hline IR0102 & Echinochloa sp. & & & & & & \\
\hline IS0001 & Cyperus rotundus & & & & & & \\
\hline JP0028 & Eragrostis curvula & & & & & & \\
\hline JP0030 & Panicum bisulcatum & & & & & & \\
\hline JP0031 & Panicum coloratum & & & & & & \\
\hline JP0033 & Eriochloa villosa & & & & & & \\
\hline JP0047 & Hordeum vulgare & & & & & & \\
\hline JP0048 & Hordeum vulgare & & & & & & \\
\hline KN0001 & Hordeum vulgare & & & & & & \\
\hline KN0006 & Hordeum vulgare & & & & & & \\
\hline $\begin{array}{ll}\text { Lc8401 } \\
\end{array}$ & Leptochloa chimensis & & & & & & \\
\hline LpKY97 & Lolium sp. & & & & & & \\
\hline ML0031 & Pennisetum sp. & & & & & & \\
\hline Pd88413 & Paspalum distichum & & & & & & \\
\hline $\begin{array}{l}\mathrm{Pg} 1054 \\
\end{array}$ & Stenotaphrum secundatum & & & & & & \\
\hline Pg1213-22 & Festuca sp. & & & & & & \\
\hline PH0052 & Cyperus rotundus & & & & & & \\
\hline PH0053 & Cyperus rotundus & & & & & & \\
\hline PH0062 & Paspalum distichum & & & & & & \\
\hline PH0075 & Brachiaria mutica & & & & & & \\
\hline PH0078 & Echinochloa sp. & & & & & & \\
\hline $\mathrm{PH} 0097$ & Paspalum paspaloides & & & & & & \\
\hline PL 2-1 & Lolium sp. & & & & & & \\
\hline PL 3-1 & Lolium sp. & & & & & & \\
\hline P28 & Bromus sp. & & & & & & \\
\hline PR0069 & Stenotaphrum secundatum & & & & & & \\
\hline Pr8202 & Panicum repens & & & & & & \\
\hline RW0043 & Eleusine coracana & & & & & & \\
\hline TF05-1 & Festuca sp. & & & & & & \\
\hline US0064 & Setaria sp. & & & & & & \\
\hline US0066 & Cenchrus ciliaris & & & & & & \\
\hline US0077 & Lolium perenne & & & & & & \\
\hline US0078 & Lolium perenne & & & & & & \\
\hline US0084 & Stenotaphrum secundatum & & & & & & \\
\hline $\begin{array}{ll}\text { VT0032 } \\
\end{array}$ & Leersia hexandra & & & & & & \\
\hline
\end{tabular}

Fig. 2. List of Pyricularia oryzae isolates used to assess the specificity and inclusivity of the selected primer/probe combinations in real-time PCR. The color of the boxes indicates the amplification status of the 114 DNA extracts tested using primer sets C5, C9, C17, C19, and MoT3 (dark gray = amplification, light gray = late amplification, and white = no amplification). Last column (red) corresponds to the C17 primer set test using optimized quantitative PCR parameters (including higher hybridization temperature). Isolates in blue characters were genetically assigned to the Triticum lineage by Gladieux et al. (2018). 
Sanger-sequence the entire locus. Sequencing confirmed that isolates CR0023, CR0057, and JP0033 shared 100\% identity with Triticum lineage isolates at this locus. Within the C17-F/-R amplicon, a single-nucleotide polymorphism (SNP) was identified for isolate CR0023. Sequencing isolate IN0113 showed that the C17F primer's target region differed by two substitutions, located near the $3^{\prime}$ end (Supplementary Fig. S1). These substitutions lead to the appearance of a sequence that is identical to the last five bases at the $3^{\prime}$ end of C17's forward primer and could explain the late amplification of this DNA at a lower hybridization temperature. The pathogenicity of isolates CR0023, CR0057, and JP0033 was assessed by two methods. A brush inoculation confirmed the high leaf susceptibility of the wheat variety Thésée to wheat-borne isolates BR0032 and BL0028. Concerning non-wheat-borne isolates, except for CR0023, no reaction was observed. With isolate CR0023, limited necrosis could be observed at the margin or in the central vein of the leaves with this brush inoculation protocol for 5 of the 12 leaves inoculated. Spraying conidia on wheat cultivar leaves as well as on susceptible ryegrass varieties is a less invasive method that mimics the natural inoculation process. Using this inoculation protocol, none of the non-wheat-borne isolates tested induced any symptoms on wheat leaves but they created at least one lesion on susceptible checks of ryegrass, confirming their pathogenic potential in these conditions. On ryegrass, the strongest symptoms were observed for CR0023 (sampled from Echinochloa crus-galli), intermediate symptoms for CR0057 (Lolium sp.) and only one lesion was observed for JP0033 (Eriochloa villosa) on ryegrass. Finally, because DNA from AG0055 isolated from Bromus spp. cross-reacted with the MoT3-based PCR test (Pieck et al. 2017) in our conditions, and because no genomic data are available concerning this isolate to validate the lineage it belongs to, this isolate was inoculated during the same experiment on wheat leaves (leaf brush) to validate its incompatibility with this host. This isolate was not able to induce any symptoms and, therefore, was deemed unable to infect wheat (Supplementary Fig. S2).

\section{Discussion}

Infecting a novel host is a major route of transmission in the emergence of infectious disease (Giraud et al. 2010; Gladieux et al. 2015). The management of new emerging diseases requires tools that can discriminate between emerging and established populations, in order to detect the pathogen at the earliest point and to monitor and limit its spread. Detection based on DNA amplification is a rapid and sensitive alternative to morphology-based identification and to pathogenicity testing and, today, is favored for infraspecific detection (Feau et al. 2018; Firth and Lipkin 2013). Indeed, morphology-based
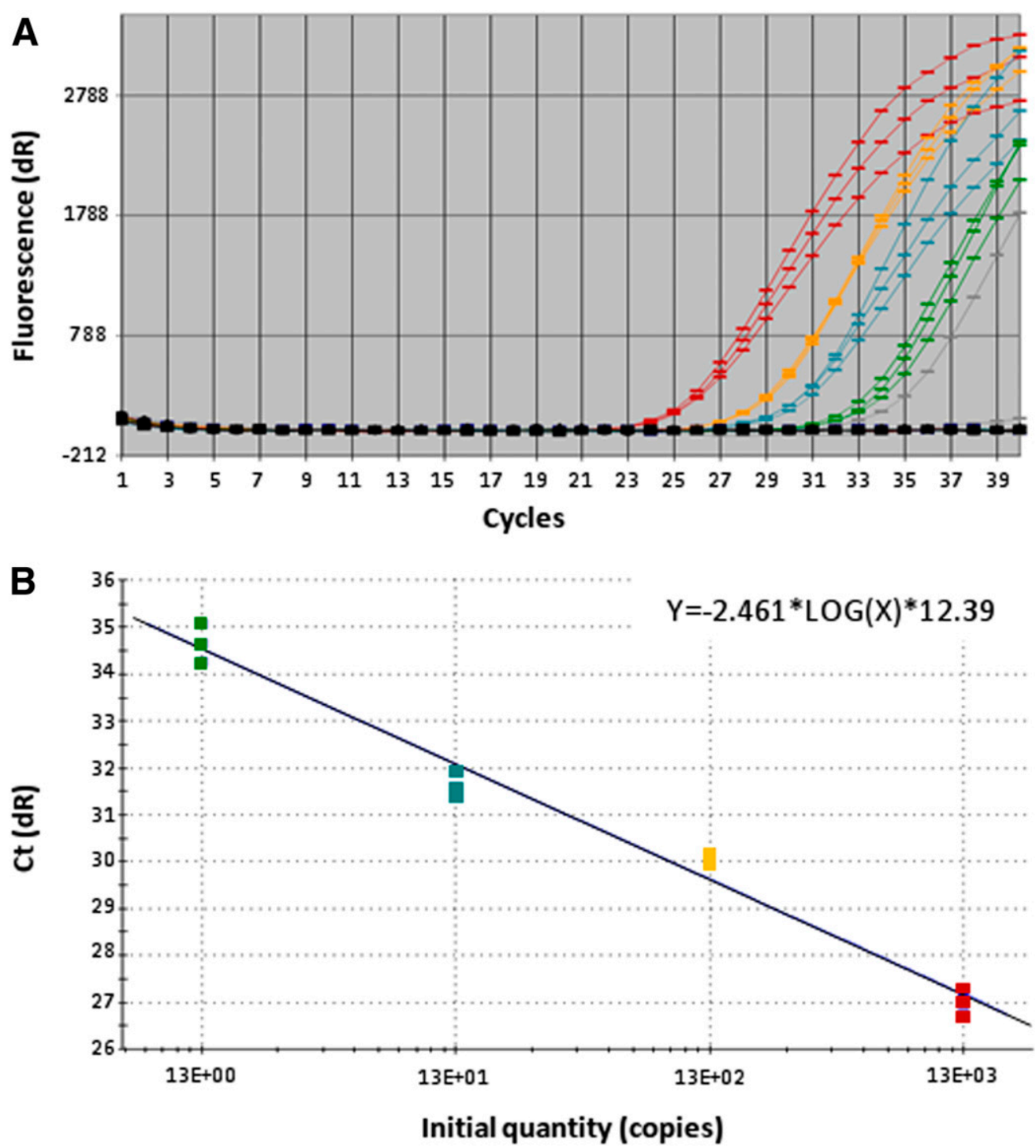

Fig. 3. Sensitivity of the primer set C17 analyzed using a 10-fold serial dilution of plasmid DNA for positive control: gray $=1.3 \mathrm{copies} / \mu \mathrm{l}$, green $=13 \mathrm{copies} / \mu \mathrm{l}$, blue $=13 \mathrm{E}+01$ copies $/ \mu \mathrm{l}$, yellow $=13 \mathrm{E}+02 \mathrm{copies} / \mu \mathrm{l}$, and red $=13 \mathrm{E}+03$ copies $/ \mu \mathrm{l})$. A, Amplification plot of a serial plasmidic 10 -fold dilution and $\mathrm{B}$, associated standard curve. $\mathrm{Ct}=\mathrm{cycle}$ threshold. 
identification is generally not diagnostic at the infraspecific scale in fungi, whereas pathogenicity tests are resource consuming and their outcome may be unclear (for instance, if the isolates surveyed represent opportunistic infections and do not constitute a self-sustainable population on the new host). The DNA-detection method can target either known host specificity determinants or other markers specific to the subgroup of isolates infecting a particular host (Bühlmann et al. 2013; Fernandez and Orth 2018; Franco Ortega et al. 2018; Singh and Kapoor 2018; Van Dam et al. 2018). In this study, an overall genome comparison of 81 assembled genomes enabled the identification of 323 polymorphisms specific to the Triticum lineage of $P$. oryzae, the causal agent of wheat blast. Some of these polymorphisms were successfully exploited to develop a qPCR-based detection test that specifically targets these positions, facilitating diagnosis of the causal agent in any particular case of wheat blast. We conducted an extensive validation process to clearly identify this detection test's limits, analyzing its inclusivity, specificity, sensitivity, robustness, and transferability.

Before starting an extensive search for new genetic targets to design a diagnostic test, we set out to assess the usability of previously described determinants of host specificity as markers specific to the Triticum lineage of $P$. oryzae. Inoue et al. (2017) showed that functional losses of the PWT3 and PWT4 effectors, which trigger an immune response in wheat varieties carrying cognate resistance genes, were key determinants in the spread of $P$. oryzae as a wheat pathogen, suggesting that $P W T 3$ and $P W T 4$ alleles would be ideal genetic markers for discriminating the Triticum lineage from other lineages. Our study clearly showed high sequence heterogeneity of PWT3 within the Triticum lineage and allele sharing between the Triticum lineage and other lineages. This pattern can be explained by several evolutionary scenarios, including the emergence of the Triticum lineage through admixture with several other lineages, incomplete lineage sorting at these genes, or gene flow into the Triticum lineage subsequent to its emergence. Regardless of the cause of allelic polymorphism at PWT3 and PWT4, no allele was specific to the Triticum lineage, thus precluding the use of these genes as targets for specific markers.

As an alternative means to identify further regions specific to the Triticum lineage, we developed a bioinformatics approach based on comparing the genomes from $P$. oryzae isolates of different lineages. We also included four genomes from $P$. grisea isolates and one genome from $P$. pennisetigena isolates. Our approach was not designed to find all polymorphisms specific to the Triticum lineage but to select only those located in fixed regions of the Triticum lineage. In fact, the only SNPs selected were Triticum-specific and identified in fixed 500-bp sequences of Triticum lineage genomes. Interestingly, the 323 polymorphisms identified were not evenly scattered all over the genome but clustered in a limited number of regions, with $88 \%$ of polymorphisms found between positions 348,000 and 720,750 of scaffold 15 of the reference Triticum-lineage genome BR0032, and $11 \%$ of polymorphisms found between positions 216,750 and 595,750 of scaffold 17. In all, almost all of the positions found $(99 \%)$ were concentrated in two regions accounting for less than $2 \%$ of the reference genome. These two regions may have experienced positive selection in the Triticum lineage, or may be linked to regions that have experienced positive selection. Therefore, the regions under positive selection might be functionally important in terms of pathogenicity to wheat. A similar strategy was used to detect the MoT3 marker (Pieck et al. 2017) but, though both studies have investigated the same pathogen species, this study used different genomic regions. In fact, several key parameters differed between the two studies, such as the reference genome (isolate B2 versus isolate BR0032), number of genomes studied, and threshold value used for selecting genome fragments. This example highlights that these parameters strongly affect the output when performing genome comparisons.

Based on the set of candidate-specific positions identified, 34 primer pairs were designed. These primers' specificity (ability to detect only isolates of Triticum lineage) and inclusivity (ability to detect any isolate of Triticum lineage regardless of origin) was checked using DNA samples that represented a set of isolates broader than that which was used in the bioinformatics detection process. The surveyed isolates' host of origin was known but, for most of them, genetic data were not available to confirm their lineage. However, all of the isolates in our study that were sampled on wheat (referred to here as wheat-borne isolates) were obtained from wheat blast epidemics. Of the 34 initially designed primer pairs, 14 showed stronger affinity to DNA from wheat-borne isolates. This high ratio confirmed the efficiency of our bioinformatics approach in identifying positions specific to a particular lineage within a species. However, in several cases, there were very few differences between targeted sequences of wheat-borne isolates and non-wheat-borne isolates, sometimes down to one SNP. The high sequence identity likely enabled a

\begin{tabular}{|c|c|c|c|c|c|c|c|c|c|c|c|c|}
\hline & & \multicolumn{6}{|c|}{ ROBUSTNESS } & \multicolumn{4}{|c|}{ TRANSFERABILITY } \\
\hline & & HYBRIDIZATION T $^{\circ}$ & 63 & 67 & 65 & 65 & 65 & 65 & 65 & 65 & 65 & 65 \\
\hline & & DNA VOLUME & 2 & 2 & 1.8 & 2.2 & 2 & 2 & 2 & 2 & 2 & 2 \\
\hline & & TOTAL VOLUME & 20 & 20 & 20 & 20 & 18 & 22 & 20 & 20 & 20 & 20 \\
\hline & & THERM O CYCLER & A & A & A & A & A & A & $\bar{B}$ & $\bar{B}$ & $\bar{B}$ & $\bar{B}$ \\
\hline & & $\mathrm{K} \pi$ & 1 & 1 & 1 & 1 & 1 & 1 & 1 & 2 & 3 & 4 \\
\hline \multirow{7}{*}{ 至 } & \multirow{2}{*}{$\begin{array}{l}\frac{\text { Dू }}{\bar{n}} \\
\frac{\pi}{2} \\
\frac{\pi}{2}\end{array}$} & $100 \times T+L O D$ & $\begin{array}{l}29.6 \\
+-0.1\end{array}$ & $\begin{array}{c}30 \\
+\cdot 0.3\end{array}$ & $\begin{array}{l}29.4 \\
+-0.1\end{array}$ & $\begin{array}{l}29.5 \\
+-0.1\end{array}$ & $\begin{array}{r}29.1 \\
+-0.2\end{array}$ & $\begin{array}{r}29.6 \\
+-0.2\end{array}$ & $\begin{array}{l}22.2 \\
+.0 .1\end{array}$ & $\begin{array}{l}22.7 \\
+-0.2\end{array}$ & $\begin{array}{l}22.5 \\
+-0.2\end{array}$ & $\begin{array}{r}22.9 \\
+-0.1\end{array}$ \\
\hline & & $10 \times T+L O D$ & $\begin{array}{r}31.4 \\
+-0.3\end{array}$ & $\begin{array}{r}32.36 \\
+.0 .5\end{array}$ & $\begin{array}{r}31.9 \\
+-0.3\end{array}$ & $\begin{array}{l}32.2 \\
+-0.2\end{array}$ & $\begin{array}{r}30.9 \\
+.0 .2\end{array}$ & $\begin{array}{l}\mathbf{3 1 . 4} \\
+-0.3\end{array}$ & $\begin{array}{l}25.8 \\
+.0 .4\end{array}$ & $\begin{array}{l}26.3 \\
+-0.1\end{array}$ & $\begin{array}{c}25.4 \\
+.0\end{array}$ & $\begin{array}{l}\mathbf{2 6 . 4} \\
+-0.1\end{array}$ \\
\hline & \multirow{3}{*}{ 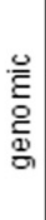 } & (wheat) BL0044 & $\begin{array}{l}27.1 \\
+.02\end{array}$ & $\begin{array}{l}27.3 \\
+.02\end{array}$ & $\begin{array}{l}27.1 \\
+.0 .1\end{array}$ & $\begin{array}{l}26.8 \\
+.02\end{array}$ & $\begin{array}{c}27 \\
+-0.2\end{array}$ & $\begin{array}{l}26.9 \\
+.0 .1\end{array}$ & $\begin{array}{r}24.4 \\
++0.3\end{array}$ & $\begin{array}{l}25.8 \\
+.0 .2\end{array}$ & $\begin{array}{l}25.7 \\
+.0 .5\end{array}$ & $\begin{array}{r}24.9 \\
+.03\end{array}$ \\
\hline & & (ele usine) IN0113 & 38.83 & - & - & - & - & - & - & - & - & - \\
\hline & & (lolium) AG0064 & - & - & - & - & - & - & - & - & - & - \\
\hline & \multirow[t]{2}{*}{$\frac{5}{8}$} & inoculated se eds & 31.8 & 32.2 & 32 & 31.4 & 31.6 & 31.7 & 25.2 & 25.6 & 25.8 & 25.6 \\
\hline & & non-inoculated seeds & - & - & - & - & - & - & - & - & - & - \\
\hline
\end{tabular}

Fig. 4. Assessment of $C 17$ test performance measuring amplification signals under different $P C R$ conditions by varying hybridization temperature, DNA volume, total volume of PCR mix, thermocycler (A = Stratagene Mx3005P and B = Corbett rotor-gene 6005), or PCR kit brand ( 1 = Core kit NO ROX, Eurogentec; $2=2 \times$ Takyon for Probe Assay, No ROX blue; 3 = LightCycler 480 Probes Master; and 4 = Takyon Core Kit for Probe Assay, No ROX blue). 
sufficient annealing of the primers to non-wheat-borne isolate DNA. This combination would have resulted in the weak nonspecific amplifications sometimes observed. Finally, five primer pairs successfully amplified only the two DNA extracts from wheat-borne isolates in the reduced panel, and four of them were considered for the development of a diagnostic test. Triticum lineage-specific hydrolysis probes were designed for each of these four primer pairs. The inclusivity and specificity of these primer/probe combinations were challenged by real-time PCR reactions with DNA from a wide range of $111 P$. oryzae, including 30 wheat-borne isolates and $81 P$. oryzae isolates sampled on other members of the Poaceae family. We also included the previously published MoT3 test (Pieck et al. 2017) for comparison. All primer/probe combinations tested (C5, C9, C17, $\mathrm{C} 19$, and MoT3) proved to be highly but not $100 \%$ specific. Because nondetection of Triticum lineage isolates could lead to the introduction of the pathogen in disease-free regions with potentially disastrous consequences, we ultimately selected the C17-F/-R/-P set that was able to amplify DNA from $100 \%$ of the wheat-borne isolates of our panel. Surprisingly, false-positive results were observed when C17 real-time PCR was carried out with DNA from four isolates that had not been sampled on wheat. DNA from isolates CR0023, CR0057, and JP0033 was amplified with a Ct value equivalent to Triticum lineage isolates while that of IN0113 led to a late amplification signal. These isolates had originally been sampled on wild Poaceae spp. in Asia: CR0023 had been sampled on Echinochloa crus-galli in Korea, CR0057 on Lolium spp. in Korea, JP0033 on Eriochloa villosa in Japan, and IN0113 on Eleusine spp. in India. Sequencing the genomic region targeted by the $\mathrm{C} 17-\mathrm{F} / \mathrm{R}$ primers confirmed that CR0023, CR0057, and JP0033 carried a sequence 100\% identical to that targeted for Triticum lineage isolate. Such patterns (i.e., isolates carrying genomic regions specific to another lineage) have previously been observed in P. oryzae (Gladieux et al. 2018; Inoue et al. 2017) and explained by gene flows between lineages. In our case, wheat blast epidemics have never occurred in Japan or Korea, which rules out the possibility that these isolates belong to the Triticum lineage or are due to recent genetic exchanges between these isolates and Triticum lineage isolates. Furthermore, these isolates were also positive in the $\mathrm{C} 5$ and $\mathrm{C} 9$ tests designed on the same scaffold of the BR0032 genome, suggesting that they actually share a significant genomic stretch with Triticum lineage isolates and making the hypothesis of a convergent evolution unlikely. Given these facts, the hypothesis of incomplete lineage sorting is favored to explain these "false positives". Pathotyping tests confirmed that these three isolates were not able to infect wheat by spraying a suspension of $20,000 \mathrm{conidia} / \mathrm{ml}$ on wheat leaves and, thus, would unlikely occur on wheat showing blast symptoms. In addition, C17-F/-R amplicon sequencing confirmed that the target sequence in IN0113 is comparable with nonTriticum lineage isolates but differs by two SNPs, thus allowing weak primer annealing and, therefore, resulting in a late amplification signal by PCR. This nonspecific amplification could be avoided by increasing the hybridization temperature during the amplification cycle.

It was essential to evaluate the performance values of the $\mathrm{C} 17$ test in order to validate the method and highlight potential drawbacks. In our conditions, the test proved highly repeatable and reproducible. The limit of detection was very low, with the test consistently able to detect as few as 13 plasmid copies of the target per PCR tube (or $1 \mathrm{pg}$ of genomic wheat blast DNA), and the detection of Triticum lineage DNA in wheat seed was successful. Our experiments confirmed the test's robustness by showing that small errors or drifts in temperature or volume would not qualitatively affect its sensitivity. However, we observed that using other brands or types of real-time PCR master mix than the ones originally used here for optimization may lead to weak cross-amplification of DNA from Eleusine isolate IN0113. This transferability assay confirmed that caution is required when a PCR protocol is implemented in conditions deviating from the original description (Ioos et al. 2019). This observation has recently been confirmed by additional data regarding the specificity of the MoT3 test (Gupta et al. 2019; Yasuhara-Bell et al. 2019).
The C17 diagnostic test developed here improves the detection of wheat blast to the extent of detecting Triticum lineage isolates that had, in previously available tests, been undetectable. On the one hand, the $\mathrm{C} 17$ test proved able to detect all epidemic wheat blast isolates in our possession. They consisted of 20 isolates belonging to the Triticum lineage tested by in silico analysis, and 30 isolates sampled on wheat with blast symptoms that were then tested by wet lab analysis. These 48 isolates had been sampled between 1988 and 2018 in five countries affected by the disease and, thus, cover a significant proportion of their genetic diversity. In our conditions, the MoT3 test (Pieck et al. 2017) failed to yield positive results for two of them (BR0032 and BR0043) by real-time PCR. On the other hand, the $\mathrm{C} 17$ test yielded false-positive results with DNA from three $P$. oryzae isolates not sampled on wheat; namely, CR0023, CR0057, and JP0033. We demonstrated that all three isolates were unable to induce any symptoms when inoculated by spray on a susceptible variety of wheat. Therefore, the presence of these genotypes on wheat blast showing symptoms is very unlikely and false-positive results are not expected when testing wheat tissue with the $\mathrm{C} 17$ test.

Prior to this study, it had been hypothesized that the isolates causing wheat blast epidemics belong to a species distinct from $P$. oryzae, and the concept of host specificity within $P$. oryzae had also been questioned (Castroagudín et al. 2016; Ceresini et al. 2019, 2018). However, further studies had refuted this hypothesis by explaining the biases that may have led to such a conclusion (Gladieux et al. 2018; Valent et al. 2019). In the present study, we chose to develop a test targeting isolates from the Triticum lineage of $P$. oryzae as described by Gladieux et al. (2018), assuming that only isolates belonging to the Triticum lineage are able to cause wheat blast epidemics. Under this assumption, the $\mathrm{C} 17$ test represents an efficient means to quickly assess whether any $P$. oryzae isolate sampled on wheat could lead to a wheat blast epidemic (with a positive $\mathrm{C} 17$ result) or, alternatively, belongs to a closely related lineage, only capable of causing opportunistic wheat infections (with a negative C17 result), such as the WBKY11 isolate in Kentucky (Farman et al. 2017). This rationale was validated because all of the isolates sampled on wheat affected by wheat blast epidemics yielded positive results with the $\mathrm{C} 17$ test. However, it is known that isolates belonging to other $P$. oryzae lineages can cause opportunistic infections on wheat and, if a new independent host jump were to occur with such isolates, it is very likely that these isolates would have a distinct genetic background and would remain undetectable by tests targeting markers specific to the Triticum lineage such as the one described here. Therefore, new wheat blast outbreaks should be thoroughly investigated.

The $\mathrm{C} 17$ test would be useful in studying the epidemiology and spread of wheat blast. In particular, it could be used to assess whether other members of the Poaceae family are a reservoir for Triticum lineage isolates. It is important to note, however, that some isolates sampled on hosts other than wheat generated false-positive results. Therefore, when testing isolates sampled on other species of Poaceae, all positive results should be confirmed using at least one other complementary test (DNA based or by pathotyping the isolate), especially in areas where wheat blast has not previously been reported. Finally, using an appropriate sampling strategy, the real-time PCR tool we developed may also be very useful for safeguarding wheat seed trade, and preventing the introduction of wheat blast disease in areas where it has been absent thus far. Wheat blast is seed borne and seed transmitted (Goulart 1988). Our preliminary experiments on artificially contaminated wheat seed suggest that the C17 test is able to detect Triticum lineage DNA in this matrix but, nonetheless, this result should be validated with naturally contaminated seed lots.

\section{Literature Cited}

Aman, A. 2016. "Wheat blast" threatens yield. Daily Star. https://www thedailystar.net/backpage/wheat-blast-threatens-yield-784372

Anjos, J., Da Silva, D. B., D'Avila Charchar, M. J., and Rodrigues, G. C. 1996. Occurrence of blast fungus (Pyricularia grisea) on wheat and rye in the savanna region of central Brazil. Pesq. Agropec. Bras. 31:79-82. 
Asuyama, H. 1963. Morphology, taxonomy, host range, and life cycle of Piricularia oryzae. In: The Rice Blast Disease: Proc. Symp. Int. Rice Res. Inst. John Hopkins Press. Baltimore, MD, U.S.A.

Bühlmann, A., Pothier, J. F., Tomlinson, J. A., Frey, J. E., Boonham, N., Smits, T. H. M., and Duffy, B. 2013. Genomics-informed design of loop-mediated isothermal amplification for detection of phytopathogenic Xanthomonas arboricola pv. pruni at the intraspecific level. Plant Pathol. 62:475-484.

Castroagudín, V. L., Moreira, S. I., Pereira, D. A. S., Moreira, S. S., Brunner, P. C., Maciel, J. L. N., Crous, P. W., McDonald, B. A., Alves, E., and Ceresini, P. C. 2016. Pyricularia graminis-tritici, a new Pyricularia species causing wheat blast. Persoonia Mol. Phylogeny Evol. Fungi 37:199-216.

Ceresini, P. C., Castroagudín, V. L., Rodrigues, F. Á., Rios, J. A., Aucique-Pérez, C. E., Moreira, S. I., Croll, D., Alves, E., de Carvalho, G., Maciel, J. L. N., and McDonald, B. A. 2019. Wheat blast: From its origins in South America to its emergence as a global threat. Mol. Plant Pathol. 20:155-172.

Ceresini, P. C., Castroagudín, V. L., Rodrigues, F. Á., Rios, J. A., Eduardo Aucique-Pérez, C., Moreira, S. I., Alves, E., Croll, D., and Maciel, J. L. N. 2018. Wheat blast: Past, present, and future. Annu. Rev. Phytopathol. 56: 427-456.

Cesari, S., Thilliez, G., Ribot, C., Chalvon, V., Michel, C., Jauneau, A., Rivas, S., Alaux, L., Kanzaki, H., Okuyama, Y., Morel, J.-B., Fournier, E., Tharreau, D., Terauchi, R., and Kroj, T. 2013. The rice resistance protein pair RGA4/RGA5 recognizes the Magnaporthe oryzae effectors AVR-Pia and AVR1-CO39 by direct binding. Plant Cell 25:1463-1481.

Couch, B. C., Fudal, I., Lebrun, M.-H., Tharreau, D., Valent, B., van Kim, P., Nottéghem, J.-L., and Kohn, L. M. 2005. Origins of host-specific populations of the blast pathogen Magnaporthe oryzae in crop domestication with subsequent expansion of pandemic clones on rice and weeds of rice. Genetics 170:613-630.

Cruz, C. D., and Valent, B. 2017. Wheat blast disease: Danger on the move. Trop. Plant Pathol. 42:210-222.

Farman, M., Peterson, G., Chen, L., Starnes, J., Valent, B., Bachi, P., Murdock, L., Hershman, D., Pedley, K., Fernandes, J. M., and Bavaresco, J. 2017. The Lolium pathotype of Magnaporthe oryzae recovered from a single blasted wheat plant in the United States. Plant Dis. 101:684-692.

Feau, N., Beauseigle, S., Bergeron, M.-J., Bilodeau, G. J., Birol, I., CervantesArango, S., Dhillon, B., Dale, A. L., Herath, P., Jones, S. J. M., Lamarche, J., Ojeda, D. I., Sakalidis, M. L., Taylor, G., Tsui, C. K. M., Uzunovic, A., Yueh, H., Tanguay, P., and Hamelin, R. C. 2018. Genome-enhanced detection and identification (GEDI) of plant pathogens. PeerJ 6:e4392.

Fernandez, J., and Orth, K. 2018. Rise of a cereal killer: The biology of Magnaporthe oryzae biotrophic growth. Trends Microbiol. 26:582:597.

Firth, C., and Lipkin, W. I. 2013. The genomics of emerging pathogens. Annu. Rev. Genomics Hum. Genet. 14:281-300.

Fisher, M. C., Henk, D. A., Briggs, C. J., Brownstein, J. S., Madoff, L. C., McCraw, S. L., and Gurr, S. J. 2012. Emerging fungal threats to animal, plant and ecosystem health. Nature 484:186-194.

Franco Ortega, S., Tomlinson, J., Gilardi, G., Spadaro, D., Gullino, M. L., Garibaldi, A., and Boonham, N. 2018. Rapid detection of Fusarium oxysporum f. sp. lactucae on soil, lettuce seeds and plants using loop-mediated isothermal amplification. Plant Pathol. 67:1462-1473.

Gallet, R., Fontaine, C., Bonnot, F., Milazzo, J., Tertois, C., Adreit, H., Ravigné, V., Fournier, E., and Tharreau, D. 2016. Evolution of compatibility range in the rice-Magnaporthe oryzae system: An uneven distribution of $\mathrm{R}$ genes between rice subspecies. Phytopathology 106:348-354.

Garcez, P. P., Loiola, E. C., Madeiro da Costa, R., Higa, L. M., Trindade, P., Delvecchio, R., Nascimento, J. M., Brindeiro, R., Tanuri, A., and Rehen, S. K. 2016. Zika virus impairs growth in human neurospheres and brain organoids. Science 352:816-818.

Giraud, T., Gladieux, P., and Gavrilets, S. 2010. Linking the emergence of fungal plant diseases with ecological speciation. Trends Ecol. Evol. 25:387-395.

Gladieux, P., Condon, B., Ravel, S., Soanes, D., Maciel, J. L. N., Nhani, A., Chen, L., Terauchi, R., Lebrun, M.-H., Tharreau, D., Mitchell, T., Pedley, K. F., Valent, B., Talbot, N. J., Farman, M., and Fournier, E. 2018. Gene flow between divergent cereal- and grass-specific lineages of the rice blast fungus Magnaporthe oryzae. Mol. Biol. 9:e01219-17.

Gladieux, P., Feurtey, A., Hood, M. E., Snirc, A., Clavel, J., Dutech, C., Roy, M., and Giraud, T. 2015. The population biology of fungal invasions. Mol. Ecol. 24:1969-1986

Goulart, A. 1992. Incidência da brusone (Pyricularia oryzae) em diferentes cultivares de trigo (Triticum aestivum) em condições de campo. Fitopatol. Bras. 17:321-325.

Goulart, A. C. P. 1988. Doenças transmitidas por sementes de trigo em Mato Grosso do Sul e testes de laboratório para identificação De Pyricularia oryzae cav. Em sementes de trigo. Embrapa, Dourados, Brazil.

Goulart, A. C. P., Sousa, P. G., and Urashima, A. S. 2007. Danos em trigo causados pela infecção de Pyricularia grisea [Damages in wheat caused by infection of Pyricularia grisea]. Summa Phytopathol. 33:358-363.

Gupta, D. R., Reyes Avila, C. S., Win, J., Soanes, D. M., Ryder, L. S., Croll, D., Bhattacharjee, P., Hossain, M. S., Mahmud, N. U., Mehebub, M. S., Surovy, M. Z., Rahman, M. M., Talbot, N. J., Kamoun, S., and Islam, M. T. 2019. Cautionary notes on use of the MoT3 diagnostic assay for Magnaporthe oryzae wheat and rice blast isolates. Phytopathology 109:504-508.
Igarashi, S., Igarashi, L. C., Utiamada, C. M., Kasuma, A. H., and Lopez, R. S. 1986. Pyricularia sp. em trigo. Ocurrencia de Pyricularia sp no Estado do Parana. Fitopatol. Bras. 11:351-352.

Inoue, Y., Vy, T. T. P., Yoshida, K., Asano, H., Mitsuoka, C., Asuke, S., Anh, V. L., Cumagun, C. J. R., Chuma, I., Terauchi, R., Kato, K., Mitchell, T., Valent, B., Farman, M., and Tosa, Y. 2017. Evolution of the wheat blast fungus through functional losses in a host specificity determinant. Science 357:80-83

Ioos, R., Aloi, F., Piškur, B., Guinet, C., Mullett, M., Berbegal, M., Bragança, H., Cacciola, S. O., Oskay, F., Cornejo, C., Adamson, K., Douanla-Meli, C., Kačergius, A., Martínez-Álvarez, P., Nowakowska, J. A., Luchi, N., Vettraino, A. M., Ahumada, R., Pasquali, M., Fourie, G., Kanetis, L., Alves, A., Ghelardini, L., Dvořák, M., Sanz-Ros, A., Diez, J. J., Baskarathevan, J., and Aguayo, J. 2019. Transferability of PCR-based diagnostic protocols: An international collaborative case study assessing protocols targeting the quarantine pine pathogen Fusarium circinatum. Sci. Rep. 9: Article 8195.

Ioos, S., Mallet, H.-P., Leparc Goffart, I., Gauthier, V., Cardoso, T., and Herida, M 2014. Current Zika virus epidemiology and recent epidemics. Med. Mal. Infect. 44:302-307.

Islam, M. T., Croll, D., Gladieux, P., Soanes, D. M., Persoons, A., Bhattacharjee, P., Hossain, M. S., Gupta, D. R., Rahman, M. M., Mahboob, M. G., Cook, N., Salam, M. U., Surovy, M. Z., Sancho, V. B., Maciel, J. L. N., NhaniJúnior, A., Castroagudín, V. L., de Assis Reges, J. T., Ceresini, P. C., Ravel, S., Kellner, R., Fournier, E., Tharreau, D., Lebrun, M.-H., McDonald, B. A., Stitt, T., Swan, D., Talbot, N. J., Saunders, D. G. O., Win, J., and Kamoun, S. 2016. Emergence of wheat blast in Bangladesh was caused by a South American lineage of Magnaporthe oryzae. BMC Biol. 14: Article 84.

Islam, M. T., Kim, K.-H., and Choi, J. 2019. Wheat blast in Bangladesh: The current situation and future impacts. Plant Pathol. J. 35:1-10.

Kang, S., Sweigard, J. A., and Valent, B. 1995. The $P W L$ host specificity gene family in the blast fungus Magnaporthe grisea. Mol. Plant-Microbe Interact. 8:939-948.

Kato, H., Yamamoto, M., Yamaguchi-ozaki, T., Kadouchi, H., Iwamoto, Y., Nakayashiki, H., Tosa, Y., Mayama, S., and Mori, N. 2000. Pathogenicity, mating ability and DNA restriction fragment length polymorphisms of Pyricularia populations isolated from Gramineae, Bambusideae and Zingiberaceae plants. J. Gen. Plant Pathol. 66:30-47.

Klaubauf, S., Tharreau, D., Fournier, E., Groenewald, J. Z., Crous, P. W., de Vries, R. P., and Lebrun, M.-H. 2014. Resolving the polyphyletic nature of Pyricularia (Pyriculariaceae). Stud. Mycol. 79:85-120.

Loconsole, G., Potere, O., Boscia, D., Altamura, G., Djelouah, K., Elbeaino, T., Frasheri, D., Lorusso, D., Palmisano, F., Pollastro, P., Silletti, M. R., Trisciuzzi, N., Valentini, F., Savino, V., and Saponari, M. 2014. Detection of Xylella fastidiosa in olive trees by molecular and serological methods. J. Plant Pathol. 96:7-14.

Maciel, J. L. N. 2011. Magnaporthe oryzae, the blast pathogen: Current status and options for its control. CAB Rev. Perspect. Agric. Vet. Sci. Nutr. Nat. Resour. 6: 1-8.

Malaker, P. K., Barma, N. C. D., Tiwari, T. P., Collis, W. J., Duveiller, E., Singh, P. K., Joshi, A. K., Singh, R. P., Braun, H.-J., Peterson, G. L., Pedley, K. F., Farman, M. L., and Valent, B. 2016. First report of wheat blast caused by Magnaporthe oryzae pathotype triticum in Bangladesh. Plant Dis. 100: 2330.

Malik, S. A., and Khan, M. A. 1944. Parasitic fungi of the north-west Frontier Province. Indian J. Agric. Sci. 13:522-527.

Mcrae, W. 1922. Report of the imperial mycologist: Pusa Scientific Research Institute scientific reports 1921-22. Rev. Appl. Mycol. 2:258-260.

Milazzo, J., Pordel, A., Ravel, S., and Tharreau, D. 2019. First scientific report of Pyricularia oryzae causing gray leaf spot disease on perennial ryegrass (Lolium perenne) in France. Plant Dis. 103:1024.

Morse, S. S. 2001. Factors in the emergence of infectious diseases. Pages 8-26 in: Plagues and Politics: Infectious Disease and International Policy. A. T. Price-Smith, ed. Global Issues Series. Palgrave Macmillan, London, U.K.

O’Donnell, K., Sarver, A. J. B., Brandt, M., Chang, C. D., Noble-Wang, J., Park, J. B., and Sutton, A. D. 2007. Phylogenetic diversity and microsphere arraybased genotyping of human pathogenic Fusaria, including isolates from the multistate contact lens-associated U.S. Keratitis outbreaks of 2005 and 2006. J. Clin. Microbiol. 45:2235-2248.

Ou, S. H. 1985. Rice Diseases. IRRI, CAB International, Kew, United Kingdom

Picinini, E. C., and Fernandes, J. M. C. 1990. Occurrence of wheat blast (Pyricularia oryzae) in commercial fields in the state of Rio Grande do Sul, Brazil. Fitopatol. Bras. 15:83-84.

Pieck, M. L., Ruck, A., Farman, M. L., Peterson, G. L., Stack, J. P., Valent, B., and Pedley, K. F. 2017. Genomics-based marker discovery and diagnostic assay development for wheat blast. Plant Dis. 101:103-109.

Rush, M. C., and Carver, R. B. 1973. Ryegrass blast: A serious new disease in Louisiana. La. Agric. 16:15.

Schena, L., Nigro, F., Ippolito, A., and Gallitelli, D. 2004. Real-time quantitative PCR: A new technology to detect and study phytopathogenic and antagonistic fungi. Eur. J. Plant Pathol. 110:893-908.

Singh, N., and Kapoor, R. 2018. Quick and accurate detection of Fusarium oxysporum f. sp. carthami in host tissue and soil using conventional and realtime PCR assay. World J. Microbiol. Biotechnol. 34:175. 
Te Beest, D. O., Guerber, C., and Ditmore, M. 2007. Rice Blast. Plant Health Instruct. doi:10.1094/PHI-I-2007-0313-07 https://www.apsnet.org/edcenter/ disandpath/fungalasco/pdlessons/Pages/RiceBlast.aspx

Tosa, Y., Hirata, K., Tamba, H., Nakagawa, S., Chuma, I., Isobe, C., Osue, J., Urashima, A. S., Don, L. D., Kusaba, M., Nakayashiki, H., Tanaka, A., Tani, T., Mori, N., and Mayama, S. 2004. Genetic constitution and pathogenicity of Lolium isolates of Magnaporthe oryzae in comparison with host speciesspecific pathotypes of the blast fungus. Phytopathology 94:454-462.

Valent, B., Farman, M., Tosa, Y., Begerow, D., Fournier, E., Gladieux, P., Islam, M. T., Kamoun, S., Kemler, M., Kohn, L. M., Lebrun, M.-H., Stajich, J. E., Talbot, N. J., Terauchi, R., Tharreau, D., and Zhang, N. 2019. Pyricularia graminis-tritici is not the correct species name for the wheat blast fungus: Response to Ceresini et al. (MPP 20:2). Mol. Plant Pathol. 20:173-179.

Van Dam, P., De Sain, M., Ter Horst, A., Van der Gragt, M., and Rep, M. 2018. Use of comparative genomics-based markers for discrimination of host specificity in Fusarium oxysporum. Appl. Environ. Microbiol. 84: e01868-17.

White, T. J., Bruns, T. D., Lee, S. B., and Taylor, J. W. 1990. Amplification and direct sequencing of fungal ribosomal RNA genes for phylogenetics. Pages 315-322 in: PCR Protocols: A Guide to Methods and Applications. M. A. Innis, D. H. Gelfand, J. J. Sninsky, and T. J. White, eds. Academic Press, San Diego, CA, U.S.A.

Yasuhara-Bell, J., Pedley, K. F., Farman, M., Valent, B., and Stack, J. P. 2018. Specific detection of the wheat blast pathogen (Magnaporthe oryzae Triticum) by loop-mediated isothermal amplification. Plant Dis. 102: 2550-2559.

Yasuhara-Bell, J., Pieck, M. L., Ruck, A., Farman, M., Peterson, G. L., Stack, J. P., Valent, B., and Pedley, K. F. 2019. A response to Gupta et al. (2019) regarding the MoT3 wheat blast diagnostic assay. Phytopathology 109 509-511. 